Review Article

\title{
Thresholds of body and mind
}

\author{
Andrew Hague* \\ President of CellSonic Limited, Manufacturers of Medical Equipment, UK
}

*Corresponding author: Andrew Hague, President of CellSonic Limited, Manufacturers of Medical Equipment, UK.

Received Date: February 17, 2021

Published Date: March 17, 2021

\begin{abstract}
What are the limits? How much can we endure? What will be tolerated. When does anguish start? These limits are the thresholds beyond which suffering starts. They have a direct effect on the immune system which interacts between the body and the mind. It is our built-in, automatic doctor.
\end{abstract}

Keywords: Immune system; Tolerance; Cancer; Panic; Determination; EMF; Electromagnetic Field; 5G; Oblivion; Post-Traumatic Stress Disorder; PTSD; Democracy; Malaria; Slavery; Quinine; Transplants; Electroporation; Antibiotics; Antibiotic resistance; CellSonic VIPP; Thresholds

\section{The immune System}

The importance of the immune system correcting illness is well understood. We know when it is weak because we have caught a cold but cannot measure it. There seems to be no way of knowing that the immune system is working at $100 \%$ efficiency. The best we can do is follow good advice to keep healthy which means doing what supports the immune system to protects us from illness.

The link between the body and brain is known. A healthy body is essential for an efficient brain and a bright brain warns the body of dangers. Every cell in the body is linked to the brain. The contents of the brain are called the mind. These are our thoughts and emotions. They have a direct influence on the immune system. It is difficult to control thoughts, but they have to be controlled to avoid throwing our automatic health protection off balance and over the threshold.

\section{Antibiotic Resistance}

The body has a threshold of tolerance to antibiotics. The more it encounters antibiotics, the more it becomes resistant. This is a problem because antibiotics are used for warding off infection and if they become ineffective, what other method can be used to fight the infection? About half the amount of antibiotics consumed are to protect against any infection that may have been caught during surgical operations.

Not using antibiotics after surgery would reduce their consumption considerably saving a lot of money and suffering. It is not just the development of the resistance that worries doctors, it is the environmental contamination from antibiotics that flow from people into rivers and the sea and then into fish which humans eat. The sewage treatment plants do not take out the antibiotics. A similar problem was found in The Netherlands many years ago with growth hormones fed to cattle in Germany up stream of the rivers from which The Netherlands takes its drinking water. As the joke says, the Dutch drinking water is good; it has already been drunk six times before by Germans. The result was that the hormone that increased the size of cattle also worked on people and the Dutch became bigger. This contamination has been controlled and stands as a warning that there is a limit to the cleansing of water [1].

The answer is to use antibiotics less and this is practical. All surgical operations should end with a CellSonic VIPP treatment. As is well know from the healing of external and internal wounds [2], CellSonic is the best method, no drugs are used, there are no side 
effects and infection is killed even when it is deep inside the body. A pharmaceutical antibiotic destroys a patient's digestive bacteria depriving them of nutrients in their food and does not always catch the particular germ preventing a wound closing. CellSonic kills viruses, bacteria and parasites. It also puts more oxygen in the blood and sends stem cells to the wound to form new tissue.

There is a considerable cost saving by using CellSonic compared to drugs.

Where patients who have not had surgery need to kill bacteria, they may then have antibiotics. As the preponderance of these drugs is less, their side effects are less and the evolution of resistance to antibiotics is reduced.

\section{An Inflexible Threshold}

Many medical conditions tolerate a wide range of invasion but there is one, a killer, where there is little latitude and that is the amount of blood we need. Exsanguination is the loss of blood called hypovolemic or low-volume shock. People can die from losing half to two-thirds of their blood. On average, it takes about 45 seconds for blood to circulate from the heart, all around the body, and back to the heart again. An average adult's heart beats more than 100,000 times a day.

The brain needs the heart to supply it with blood containing oxygen that it gets from the lungs. The blood has to be cleaned by the liver. These are necessities, a threshold with no latitudes. Amazingly, people will allow their liver to be damaged by alcohol. The arteries and veins carrying blood become blocked by thickened blood and lack of exercise. The lungs are damaged by tobacco and other smoke. All these injuries are avoidable. Some are widely known, and others are only just beginning to be understood and here I refer to electromagnetic fields.

The heart can be damaged beyond repair. The first heart transplant was done by Christiaan Barnard in South Africa on 3 December 1967. I remember it being headline news for days and Barnard became a household word. Many years later when I had started in the medical business, I supplied Dr Bernd Ketzer with a Swiss made early version of the CellSonic machine to his orthopaedic department at Pinderfields Hospital in Yorkshire in England. Over dinner one evening he told me that in South Africa he had worked with Barnard and I was impressed believing that the heart transplant was the ultimate surgical operation. Not at all. What Dr Ketzer told me was almost beyond belief and as it has never been contradicted, I report it now. Barnard was a determined, brilliant man who would get his own way. He performed a few body transplants. If Dr Ketzer reads this and I have forgotten some details of a conversation more than twenty years ago, my apologies and do contact me. A man's head was transferred to an orangutan. Very few people could afford this operation so few transplants were done. To stay alive, the brain must be kept alive. Limbs are not needed. The essential organs are the heart, lungs (at least one), liver and kidneys (at least one). Further details, I do not have. Such are the thresholds for survival.

\section{Cancer}

The concept of a threshold is useful when understanding cancer. The immune system is central to our defence against cancer. The standard treatment of chemotherapy and radiation blocks the immune system so that our essential natural healing is prevented from working. The degradation of the immune system varies from case to case and when the threshold is crossed, the immune system stops working, cancer cells continue to proliferate, and other infections are free to breed.

We all get cancer every day. Our bodies are made of billions of cells that are replaced on average every six weeks. Each new cell should be the same as the one it replaces but occasionally that does not happen. The new cell is different, it is a mutation and will replicate profusely more copies that we call malignant. They are cancer cells. The immune system finds these mutant cells and kills them. This is the main job of the immune system. We are a new species about 80,000 years old and our organs have not settled down in the evolutionary sense; we depend on the catch and kill process to maintain good health. Sharks and ants have been around for millions of years and they do not have replicating cells. If we can survive a few million years, we too may settle down.

A weak immune system will not catch a cancer cell and leaves it to replicate. Within a year or two, a lump of cancer cells will have formed sufficient to be seen as a tumour. Cancer patients ask how they developed cancer. Enquiring into their history, there is usually a stressful period and very likely that was when their immune system was weak. Stopping the cancer is now straightforward thanks to the non-surgical, irreversible electroporation of the CellSonic VIPP machine generating blasts of pressure pulses and electrical fields lasting one nanosecond at a rate of four a second3. Pressure kills cancer and the electrical field changes the voltage across the cell from 15 millivolts to the 65 millivolts of a healthy cell. By the time a patient arrives for a cancer treatment, they are usually damaged by more than the cancer. Their immune system will have been impaired and ruined by chemotherapy and the radiation will have caused more cancer cells, not fewer.

A cancer patient's immune system has to be strengthened. This is done by diet, sleep, exercise and mostly with emotional support. So often I am told that the oncologist has advised the patient that their cancer is stage 4 . This means they cannot be cured and send the patient to a hospice to die. There is no stage 5 . The oncologist will report that the patient did not respond to treatment. They did. They were being poisoned. What else could they do?

A cancer patient in America incurs an expenditure of $\$ 200,000$ a year and dies in the fifth year. Money is involved, lots of it. The 
pharmaceutical companies known as Big Pharma make half their profits from cancer. They are the biggest, richest companies in the world. The American FDA (Food and Drugs Administration) is sponsored by them. So are medical schools. The world center for cancer is still Ukraine where the Chernobyl nuclear reactor exploded, and the cancer researchers there have been told how to stop cancer but they do not change their futile methods. The Chairman of the British National Health Service was told at a university conference in England that CellSonic cures cancer and he was uninterested. This is the state of affairs world-wide. The medical establishment has its head in the sand and is convinced that Big Pharma will eventually find a drug that changes the electrical fault of cancer into a healthy cell. Biophysical electrical faults are not cured with biochemical drugs.

\section{Liver and Kidneys}

The liver is the biggest internal organ. It is remarkable for being able to regenerate with as much as $80 \%$ removed. If only $20 \%$ of the liver is left, it can grow new cells. That $20 \%$ defines the threshold for the liver.

Table 1: This chart was compiled by Dr Ramesh Chouhan of Hyderabad in India of a lady receiving CellSonic treatments to her kidneys. She was reducing the weekly dialysis as her kidneys regained their function. New cells were regenerated.

\begin{tabular}{|c|c|c|c|c|c|c|}
\hline Name: anon & \multicolumn{2}{|c|}{ AGE: 72 YRS } & \multicolumn{4}{|c|}{ Female } \\
\hline \multirow{2}{*}{ Date } & \multirow{2}{*}{ Normal Range } & 5-Aug-17 & 18-Aug-17 & 26-Aug-17 & 17-Sep-17 & 17-Oct-17 \\
\hline & & \multicolumn{3}{|c|}{ Weekly 3 times dialysis } & Weekly 2 times dialysis & \\
\hline Creatinine, Serum & $.55-1.02$ & 4.67 & 3.89 & 5.51 & 6.27 & 5.7 \\
\hline Blood Urea & $15-40$ & 36 & 31 & 53 & 74 & 57 \\
\hline Sodium, Serum & $136-145$ & 139 & 143 & 139 & 139 & 137 \\
\hline Potassium, serum & $3.5-5.1$ & 3.8 & 3.7 & 4.5 & 4 & 3.5 \\
\hline Chloride, Serum & $98-107$ & 100 & 97 & 102 & 101 & 102 \\
\hline $\begin{array}{l}\text { Dry Weight gain between dialysis per day } \\
\text { (Grams) }\end{array}$ & $1 \mathrm{~kg}$ per day & $700 \mathrm{gms}$ & $600 \mathrm{gms}$ & $500 \mathrm{gms}$ & $400 \mathrm{gms}$ & $400 \mathrm{gms}$ \\
\hline Ultrasound R-Kidney & & $6.8 \times 3.1$ & & $6.8 \times 3.1$ & & \\
\hline ultrasound L-Kidney & & $7.0 \times 3.1$ & & $7.0 \times 3.2$ & & \\
\hline MDRD GFR & & & & & 8 & 8 \\
\hline Creatinine, Serum & $.55-1.02$ & & & & 6.27 & 6.27 \\
\hline Creatinine, Urine & $25-400$ & & & & 34.65 & 34.65 \\
\hline Creatinine Clearance Test & $80-120$ & & & & & \\
\hline Total liquid intake per day & $1 \mathrm{ltr}$ & $1 \mathrm{ltr}$ & $1 \mathrm{ltr}$ & $1 \mathrm{ltr}$ & 1.25 Ltrs & 1.25 Ltrs \\
\hline Post Dialysis day Urine output & Negligible & Negligible & After 8 hrs & 5 hrs onwards & 3 hrs onwards & 3 hrs onwards \\
\hline Total volume of Urine & & & & & $>750 \mathrm{ml}$ & $>900 \mathrm{ml}$ \\
\hline
\end{tabular}

\section{Physical improvements}

Increase of Urine output

improved appetite

Dry Skin tone turning normal

Reduced skin irritation

less gain of dry weight

reduced leg swelling

Overall improvement in health \& relief from depression, anxiety \& other problems

There is no equivalent figure for the kidneys, but they can be restored by CellSonic treatments. Regenerating new tissue is one of the amazing consequences of the pulses this machine emits. It was first observed in healing non-healing wounds of diabetics and patients who have undergone surgery. Half the number of nonhealing wounds are caused by surgery in hospital. The patient will have been given antibiotics to no avail. The same predicament faces internal wounds, and the patient is offered another operation with more side effects, more agony and more expense. Surgeons should apply CellSonic pulses to a wound at the final stage of an operation. With the stitches in place, the pulses will kill any surface and internal infection whilst also triggering the supply of stem cells and oxygenated blood [3] (Table 1).

The best report of CellSonic regenerating cells came from $\mathrm{Dr}$ Joseph Choukroun in Nice in France who restored the mandible of a lady who had been on cancer drugs for ten years. The bone regrew and new teeth were implanted on titanium stubs allowing the lady 
to live a normal life. Her option prior to CellSonic was death or the amputation of her lower jaw [4].

Cellsonic has made progress with doctors such as Choukroun in France and Chouhan in India. There are many more like them who are not members of the establishment. Choukroun is a dentist. He pioneered centrifuging blood to isolate blood plasma. He is open minded and cares about the patient. Likewise, Ramesh Chouhan from Hyderabad. He had worked with Dr Bjorn Nordenstrom, Chairman of the Nobel Prize Committee, in Stockholm and lectured on the electrical properties of cells at a conference in Ljubljana in the former Yugoslavia. By the time Ramesh got back to Hyderabad in India, his laboratory had been burned down. On the floor above were patients in a hospital ward. Thugs don't care. Forty years later when I told Ramesh about CellSonic, he thanked me for saving his life. I was confused because up to then we had never met. What I had done was make a machine that did what he and Dr Bjorn Nordenstrom [5] had predicted. For that he was grateful. No one could now accuse him of being a crank. The threshold for acceptance of medical breakthroughs is set high by regulators, not to protect patients but to deter innovation.

\section{Electro Magnetic Fields}

As I write in January 2021, the covid-19 pandemic is at its height The plague dominates everything. Vaccinations have started and Big Pharma is doing a good job, thankfully. CellSonic has a protocol to cure covid-19 but it does not prevent catching the infection. [see Appendix below] It is hard to imagine that there is something worse than covid but there is, and it is already harming everyone with government support. It is the danger of the electromagnetic fields. They are dangerous because the damage is cumulative.

Some people are more affected than others, but no one is safe. The problem is electro sensitivity. I first learned about it when I met a lady at a school who asked if we could talk outside; the lights in the room made her dizzy. She said her computer had to be wired to the modem. Wireless made her ill. Even the neighbour's Wi-Fi affected her. The main message was that this is a cumulative problem. Exposure for one night may do not lasting harm but sleep every night in that electric field and the brain is burning. Recovery when moved to a safe place can take years. The damage is especially bad on children whose brains are still growing. Never let them or anyone sleep with a smartphone under the pillow.

There are two immediate threats. The ubiquitous smartphone and 5G, the supposedly more efficient transmitter of data. The maximum duration of a phone call before injury starts is six minutes. $5 \mathrm{G}$ is never safe. Government regulators say it has been tested. Yes, it has but only for telecommunications, not for health hazards.

I was interviewed by Lloyd Burrell of Electric Sense 5 and when I heard the interview on his website it was exactly as we had spoken; there was no editing. I have heard other interviews he has done and take them to be equally as authentic. Lloyd was affected by EMFs and made it his quest to find solutions. An interview with Dr Ross Andersen in British Colombia in Canada was quite scarry. He had had cancer in the brain twice and EMFs were the cause. His business is now advising others on how to eliminate or minimise exposure to EMF. Ross admits that he used to have his phone almost permanently clamped to his head. That caused the brain cancer and even though the tumour was surgically removed the threshold of his resistance was zero. He could survive only by avoiding electrical fields. His interview tells of an hotel room in Zurich. His partner was able to fall asleep straightaway after their long-haul flight, but he couldn't. He went down to the lobby to read for an hour until he was drowsy and went back to the room ready to sleep. As soon as he lay down, he was wide awake again. This happened three times and about 2.30 am he asked reception where the internet modem is in the hotel. He was told that there is a modem on every floor and found that his bed was the other side of the wall to the modem. He wrapped his head in a special, protective blanket that he carried for such emergencies and was then able to sleep. He is resigned to always having this problem after crossing the threshold of his resistance and will forever be in danger. Many more people are sinking into the same danger that affected Ross and they don't know the cause. Nor do their doctors. Some have as many as 28 different medicines to help them; bottles of pills which inflict further damage.

The main advice is to avoid the EMFs. There are devices that partially block the fields and absorb the radiation but nothing is better than avoidance. This might not be as difficult as it first seems. Be careful where you live. Avoid overhead powerlines. Even a mile away is too close. Make sure the wiring in your house is grounded (earthed). Dr Andersen was describing a house in Canada that was not earthed and all the occupants had become ill. He inspected the house, found the fault and had a long conductive spike inserted into the ground deep enough to reach moisture. That spike was connected to the earth circuit at the fuse box.

When Dr Andersen flies, he takes a Geiger counter with him. At 40,000 feet above the earth, radiation is many times more dangerous than on the ground. Pilots and cabin crew are continuously exposed and most of them get cancer. It is a consequence of the job. Granite contains nuclear radiation. Apparently, there are some granite work tops in kitchens on which Dr Andersen would not place a baby to change its diaper (nappy). We have a lot to learn.

EMF thresholds vary from person to person, but everyone is affected and over time those who think they are unaffected will find that the cumulative damage is building up and by the nit is too late. In the 1950s, everyone smoked. The dangers of alcohol took longer to be heeded. Following the herd is seldom right. EMF is the new tobacco. Think it through carefully. It's your life [6]. 


\section{Malaria}

Man's exploitation of man has no limit. Nowadays, slavery is rightly condemned. Centuries ago, it was common place. When Europeans were developing cotton and sugar cane plantations in America and the Caribbean, they sought cheap labour and were beaten back by malaria transmitted by anopheles mosquitos carrying parasites from slaves and settlers. It was found that the west African slaves had some resistance to malaria and planters would pay three times more for Africans than for European slaves [7].

Around 1630, Jesuit missionaries in the mountains of Peru noticed locals ingesting the powdered bark of the cinchona tree when they had a fever. They had discovered quinine. The Jesuits kept their source secret and profited from it but by 1820 French chemists were able extract quinine from cinchona.

Slavery history is currently back in the news and the cruelty it inflicted is beyond doubt. From what I learned many years ago, slavery ended not because it was bad for the slaves but because it was too expensive for the owners and required organization. Employment was easier. The owner had no responsibility for a family and if the employee was not wanted, they were sacked. Slavery and its abolition were all about money, not kindness or compassion. Today, money is as powerful as it always was. Where there is compassion, it is conveyed by social media, the corrective force that technology allows to be heard, keeping the social threshold in place.

\section{The Price of Truth}

The word university is more powerful than college. Professor is more prestigious than lecturer. There is a belief that a university researches and teaches the unbiased truth and the professor is the guardian of academic honesty. I put that to the test in late 2019 by visiting some English universities on their open days. Two had medical schools. At one, a Russel Group member renowned for research, I asked the Vice Chancellor what would her reaction be to a sponsorship of $£ 20$ million ( $\$ 27$ million) for a CellSonic Faculty specialising in biophysics.

"I would dance a jig!" she replied with glee. There was no question of whether biophysics or CellSonic had merit over biochemistry. It was the money. I had proved that there is a threshold where mercenary precedes integrity.

At Cambridge University medical school, I asked a similar question without quoting a specific amount and the reply was that they would be keen to discuss further. In other words, to occupy a central position in the most highly respected academic institution in the world only sufficient money is needed. To gain the same position by scientific argument is impossible. I have since contacted both universities about the treatment of cancer and get no response.
If I called them with an offer of money, they would be at my feet. I would have crossed the threshold.

\section{The Body's Tolerance}

In 1967 I cycled from Graz in Austria to Athens in Greece going through Yugoslavia, then a country ruled by the communist dictator Tito. I had to bypass Albania by boat from Dubrovnik to Corfu. Back then, all the roads were unsurfaced, it was a hot summer and the water for my drinking bottle came from roadside pumps and wells. This was before clean water was sold in plastic bottles. I averaged over a hundred miles a day (160 kilometres) carrying my luggage in a large saddle bag. I bought food at roadside stalls. There were few opportunities to wash my hands. This did not strike me as unusual. Cycle touring in Britain was little different. My body was used to it. On the long two-week journey, I have no recollection of any illness. Riding most days with my shirt off, I soaked up sunlight taking in vitamin D that lifted my immune threshold high.

Now, my tolerance to bacteria is less and I am not sure that I am better for it. When I go to India, diarrhoea hits on the fourth day. By the end of the first week, when I am usually about to return to England, I have acclimatised.

In 1969, I was a teacher in Uganda at Kamuli College on the River Nile. Water and food were local. There were no stomach problems. I took a daily chloroquine tablet as a protection against malaria and had a mosquito net over my bed. I was well within the thresholds of safety.

\section{People's Tolerance}

Travelling through Yugoslavia, I did not know their languages but could get a sense of their attitudes. In every shop was a photo of General Tito, the dictator. People did not seem happy. In my notebook, I wrote that Yugoslavs have a chip on their shoulder; they feel under pressure and are angry but not sure who to blame. When communism collapsed and Tito died, the country split into three factions and thousands were killed. The Srebrenica massacre was the worst atrocity in Europe since the eradication of fascism. The people fought against themselves and even today are not settled.

Greece was totally different. I found the people happy-go-lucky. They did not care, did not try and took a typical Mediterranean view of what will be, will be. Some years later, their disregard allowed a military coup. The democracy they ignored was stolen from them. Eventually, people's rights returned and under the auspices of the European Union they are learning the disciplines of government.

Uganda meanwhile went from bad to worse. When I was there the white man was respected. I was mzungu. British colonialists ran the country with Indian families controlling vast swathes of sugar plantations. As the British eased out, the majority wanted power and Idi Amin took over with a military background and the support 
of violent thugs. Even today, Museveni has just won an election with his opposer, Bobby Wine, trapped in his house surrounded by soldiers "for his own protection".

Three countries that have still to master their destiny. Greece may be doing best with the backing of the EU. The people of Uganda, Bosnia, Serbia and Herzegovina know what they are missing. They see it on the smartphones, but they cannot get from where they are now to having leaders they can elect and then disagree with. Their tolerance of debate is too low. By some unfathomable reasoning, they think a strong leader will help them. It is they themselves who should take charge of themselves because when they don't, the strong leader exploits them. Ask the people of Belarus. They communicate on Telegram. Their threshold of tolerance has been crossed irreparably and it is not whether they will become democratic but when. Everyone can now communicate with everyone else. They cannot be fooled by the government. The power has moved to the people. So long as the messages are honest, the right decisions will be made. If the truth is corrupted, it will be found out and distrust will prevail. You can fool some of the people some of the time but not all the people all the time.

\section{Thresholds of the Mind}

The body has its limits and so too does the mind. I first encountered this in Norway sixty years ago. We were four teenagers on a cycle tour of the western fjords staying at youth hostels. The eldest was David who planned the route. I was the youngest, still at school. We were on a narrow path carved out of a cliff above the fjord. It led from a car park at the end of the road to a viewing platform and then joined a hiking trail that led down to a village at the head of the fjord where we would join another road. The path was wide enough to ride on but the railing at the side was the same height as the handlebars. Sitting on the saddle, there was nothing on the right except 500 feet of open air with rocks and water below. We walked. It was just wide enough to have the bike on the right and walk beside it with the cliff at our left shoulder. We had gone about a hundred yards and suddenly David shouted.

"Stop! There's been a rock fall. The path has gone. We have to go back."

I was third in the line. I turned around. Jack was behind me. When we got back to England after this tour, he was going to Cambridge to study to be a doctor. A bright lad noted for being quiet. I was surprised by what I saw. It looked as though he was about to cry. Following me, he need only look at me. Now, he would become the leader. The void scared him. The path was too narrow to turn the bike around. It had to be wheeled backwards with the pedals hitting his left leg, rear steering the handlebars and the view across the fjord in full view. The section we were on could collapse as readily as the path further along.
"I can't!" he moaned. The other two heard him and said nothing. I resisted shouting at him.

"You are alright. Just turn around slowly. Go step by step. No rush". I was as calm and yet forceful as I could be to coach him into action. He knew I was right but panic was rising and he had to act. He did as I told him.

“That's good. Look down at the path. Steady does it." He shuffled along and in what seemed like an hour we regained the road. Jack was shaking and he collapsed with his head in his hands. David found some Kendal Mint Cake [8] and gave a piece to Jack. No one spoke.

Jack's threshold for mental resilience was low. Probably up to that day, he did not know it. He had discovered something about himself. We lost touch with him after he went to Cambridge and I am sure he did well but he could never be a military doctor.

\section{The Cave Rescue $[9,10]$}

About twenty years ago I sponsored a slide lecture in Brecon in South Wales by Martin Farr, a cave explorer. He went underground into narrow passages and explained that if you get stuck, you only have to relax and let the body contract sufficiently to allow you to squeeze through. This seemed to me to be a prime example of selfcontrol and I have crossed visiting caves from my list of things to do. He pioneered a route underground from one side of the Brecon Beacons, a mountain range, to the other with much of it through flooded passages. They had to wear oxygen tanks. He told of a friend lost in caves in South Africa. By the time the immigration authorities agreed to let a rescue party from England enter the caves, the man had died.

Remembering these accounts, I was gripped by the news of the Tham Luang caves rescue in Thailand. On Saturday 23 June 2018, twelve boys aged 11 to 16 had gone into the caves with their football coach and were trapped by rising water. To escape they went further along the underground passages. Here are the boys before they went into the cave. They travelled there on their bicycles (Figure 1).

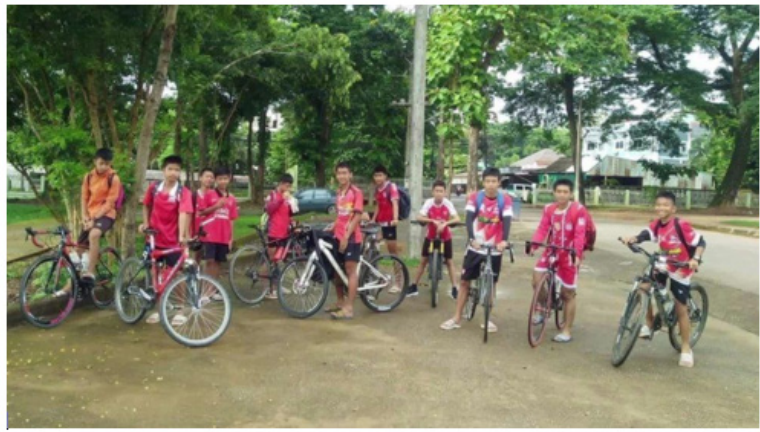

Figure 1: 
When it was realised that the group had not returned and their abandoned bicycles were found outside the cave entrance, the alarm was raised. A British caver, Vern Unsworth who lived in Thailand was by chance intending to visit the caves the next dayand he advised the Thai government. Vern knew these caves (Figure 2,3).

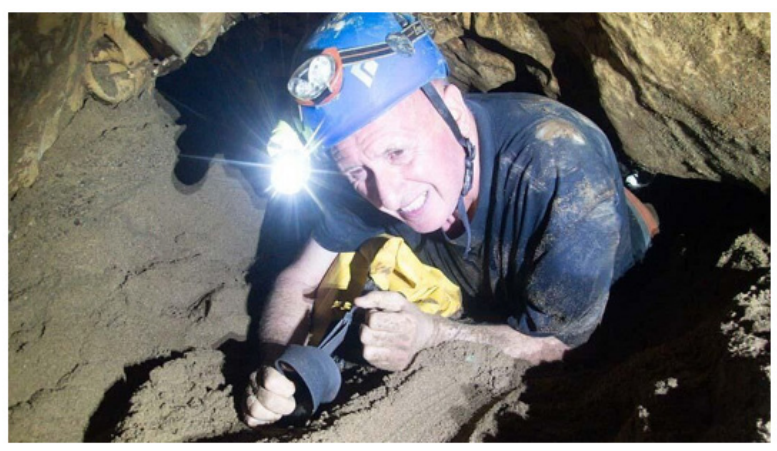

Figure 2: Vernon Unsworth in a cave.

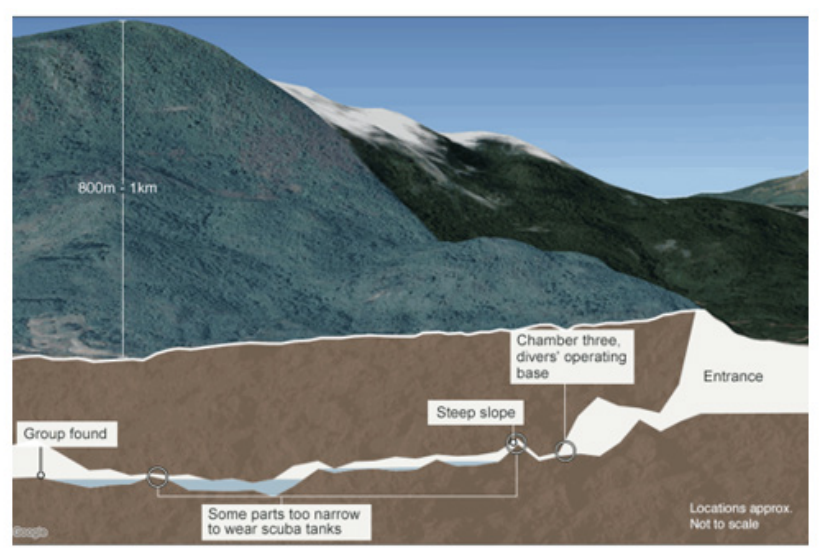

Figure 2: Cave Rescue Hazards

This cross section of the mountain shows where the boys were trapped 4 kilometers from the entrance. They were discovered on 2nd July by Richard Stanton and John Volanthen. The account of the rescue is well reported by the BBC from whom these pictures were lifted and by Wikipedia. The boys did not know how long they had been in the cave and had survived by rationing their food under the guidance of their coach who gave the food to the boys and denied himself. Much of their time was spent trying to dig an escape route. By the time the rescuers arrived, the hole was five meters deep. They had no concept of where they were or the danger, they were in. Contrast this with Jack on the cliff ledge able to see the drop below into which he feared he was about to fall. The oblivion of the trapped boys helped to maintain their sanity. When the rescue was planned and they were asked who should be taken out first, they said the ones who lived furthest away from the cave because they had to cycle home and would have furthest to go. They were all anaesthetised for the journey from the cave, so they had no knowledge of the danger they were in. Even now, as they will have been told about it, to them it is as unreal as watching a film would be. For the rescuers, it was reality.

Vernon Unsworth and the team were fully aware of the dangers. One of the Thai members, Saman Kunan, died when his oxygen supply ran out. A memorial to him now stands outside the cave. This rescuewas an extreme example of a high threshold of mental resilience. With good leadership, careful planning and determination, amazing tasks can be accomplished. They are all heroes. To quote from the BBC report written by Matthew Price and Seren Jones on 23 June 2019:

- Vernon is a calm, measured man who deals well with pressure. He's been exploring underground caves for almost 50 years - a hobby that started in his native Lancashire when he was 16.

- "The bug is finding a passage nobody's ever been into before - you know you're the first. Whatever footprints you leave, they're yours."

- It's a hobby - not his job. But it's a pastime that made him one of just a handful of people in the world who could even attempt the impossible: saving the Wild Boars football team.

\section{Medical heroes}

We see the same calm, devotion to duty and heroism today in the covid pandemic. When researchers at King's College London spoke to 709 workers at nine intensive care units in England, nearly half reported symptoms of severe anxiety, depression, post-traumatic stress disorder or problem drinking. A researcher, Neil Greenberg, said NHS workers are "suffering more than combat troops".

Medical staff did not enlist to run a death camp. They would accept that deaths were inevitable but never on the scale of the pandemic. It has thrown them off balance, exceeded their mental threshold and they struggle to remain sane but persevere because they know they are needed. Like Jack, they see the danger. They also see that there is no escape route that they can manage. The vaccinations are happening outside their wards and will hopefully lead to fewer patients. The caring staff are helpless. Not even able to do something positive as were the cave rescuers. To escape mental anguish, the carers tried to blank out the day-to-day reality. If they had a cure for covid, they would have set to work, achieved results and not suffered.

I wrote a protocol for covid-19 (see appendix below) using the CellSonic machine and sent it to the British National Health Service. I followed up with phone calls to their innovation department that was begging for help butthey would not listen. Covid has become government property. Everything is directed into government hospitals; protocols are regulated by bureaucrats and politicians 
make decisions based on what little they understand. In America and Brazil, the leaders dismissed the truth saying that the covid virus was no worse than a bad cold [11-19].

\section{Appendix}

\section{CellSonic Cancer protocol}

The patient must not be taking any cancer drugs, especially not chemotherapy or radiation. If the patient has had any cancer drugs there must be a gap of at least four weeks before CellSonic can be used.

The effect of the VIPP will open the cells which would allow poisonous cancer drugs to invade and kill the patient.

- The CellSonic VIPP treatment of cancer must not be combined with any other drugs.

- The patient must not smoke, drink alcohol, take any stimulants or eat red meat.

- A vegetarian diet is recommended with vitamin B17 known to be especially beneficial.

- $\quad$ Apply 300 shocks to each tumour at energy level 4.

There should be no more than three treatments and ideally only one treatment. If the doctor feels more treatments are needed, please contact cellsonic.beauty@gmail.com to discuss the situation. When treating the brain, apply only one treatment. Observe the patient for a few days and then discuss with CellSonic before another treatment. This is because of the absence of chalones.

From Dr Steve Haltiwanger When you educated me on the fact that CellSonic not only produced sound waves but also CellSonic produces a short duration, high powered electrical field it looks more likely that you have created a nonsurgical form of irreversible electroporation using a combination of sound waves PLUS a highpowered electric field. The combination of VIPP sound and highpowered electrical fields have never been combined before to my knowledge to treat cancer. Noble prize work if you can live to collect it. This is a paradigm-breaking disruptive technology. WOW!

I think we now have a good working theory to explain why VIPP works in cancer.

In my opinion, it is the combined effect of sound and electric field that produces the unique effects of VIPP. If you take away the short duration (nanosecond- maybe) electrical field and just use sound waves or a slower rise time electrical field, you will not see the same effects - which is why your technology is different from your competitors.

Stopping cancer with the CellSonic technique is a breakthrough. The procedure is safe. The same technology has been used on kidney stones for forty years on millions of patients in all countries with no reports of causing or spreading cancer. By diagnosing the electrical properties of cancerous tissue and immediately treating it to change the behaviour of the cells, it becomes possible to check everyone regularly so that cancer is stopped before the patient is aware of it. In other words, cancer has been conquered.

\section{The cave rescue [9]}

To the divers' knowledge, there are only three people in the world who are both elite cave divers and anaesthetists - one in the UK, one in the US, and one in Australia.

- $\quad$ The British team got in touch with the Australian, Richard "Harry" Harris.

- “Doc Harry said: 'It won't work'. He said 'it just won't work'," Vernon recalls.

- "Rick said to Harry: 'Well I'd like you to sleep on it overnight', and Harry said to Rick: 'What if I decide not to do it?"”

- $\quad$ "And Rick said: 'They all die?.'

- $\quad$ The only way they might get the boys out alive was to sedate them. They used a mixture of ketamine, xanax, and atropine to try to dry up fluids so they wouldn't choke on their own saliva.

\section{Covid stress [12]}

New research from King's College London shows nearly half of Intensive Care Unit (ICU) staff are likely to meet the threshold for PTSD, severe anxiety or problem drinking during the COVID-19 pandemic.

\section{COVID-19 Protocol with CellSonic VIPP}

- $\quad$ The patient will be treated from front and back and it does not matter which side is done first.

- The membrane of the shock head of the CellSonic machine is to be covered in ultrasound gel and the same gel applied to the body where the doctor or nurse will aim at the lungs. This is important because a pressure wave will travel from the shock head, through the gel and through the body to the lungs. The gel behaves like water and bridges the gap between the machine and the body.

- $\quad$ Set the energy level to 5 and the number of shocks (also called pulses) to 300 . Aim at the lungs.

- Understand that the lungs are encased in the rib cage so the pulses can only penetrate through the gaps between the ribs. Angle the head one way and then another to catch the covid-19 virus in the lungs. The pressure is expected to kill the virus. 
- We know from many years of wound healing that all infections, be they virus, bacteria or parasites are killed by the pressure pulses. No drugs are used so there will be no side effects.

- We also know from curing lung cancer that we do not damage the lungs. Nor is the heart damaged providing care is taken.

- When the heart is in the line of fire, so to speak, give only 50 pulses and pause a minute or two to let the patient's heart maintain its own rhythm.

- Immediately the pulses hit the virus it is expected to be killed. The immune system will sense the change and within an hour the patient should display a sense of relief. But this may not be enough. There could be more viruses hiding in places that were missed in the first attack so give a second treatment three hours later. Viruses left alive will multiply.

- Delivering 300 pulses into the lungs from the front and 300 from the back should be enough in one session. In one day, the patient could be given three sessions of treatments.

- If the patient feels sore in the throat indicating that the virus is lurking there, treat the throat from the front by aiming through the neck where gel has been applied. Pulses that hit the spinal column will not harm. We aim at the spine as a standard treatment for severed spinal cord and cancer bone marrow.

- No special diet is required other than not allowing alcohol, smoking or narcotics. A sedative may help the patient relax.

- It is advisable to use a disposable transparent barrier film whilst treating. The film will isolate the treatment head from the affected patients. Pour sufficient gel on the patient's body, place the barrier film covering more than the area to be treated, pour sufficient gel on top of the film and treat. This will avoid direct contact of treatment head with the patient.

\section{Acknowledgement}

None.

\section{Conflict of Interest}

No conflict of interest.

\section{References}

1. CellSonic wins Global Health and Pharma award for Best Non-Surgical Electroporation Technology.

2. CellSonic Beauty.

3. Wounds.

4. Cellsonic - Discovering Medical Cures. Brussels University.

5. Gaelle Leemans Extracorporeal shockwave therapy in the treatment of chronic ulceration: the effect on wound healing and on the quality of lifeInternal wounds.

6. Cancer can be cured by CellSonic VIPP.

7. Cancer Interview.

8. Choukroun Joseph, Use of shock waves to the treatment of osteonecrosis of the mandible. A non-invasive approach.

9. Cancer and Electromagnetic Energy.

10. Bjorn Nordenstrom Electrochemical Treatment of Cancer

11. Lloyd Burrell of Electricsense interviews

12. Cell phone danger and children.

13. Malaria, The Economist.

14. Achieving the impossible: Thai cave rescue.

15. Cave Rescue.

16. Dr Neil Greenberg

17. New study shows mental health of ICU staff should be immediate priority.

18. The mental health of staff working in intensive care during COVID. 